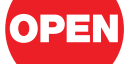

SUBJECT AREAS:

EVOLUTION

GENETIC VARIATION

ANIMAL BEHAVIOUR

PARASITOLOGY

Received

9 March 2012

Accepted

21 September 2012

Published

12 October 2012

Correspondence and requests for materials should be addressed to K.I. (kikkuo@cc.tuat. ac.jp)

\section{Environmental and genetic controls of soldier caste in a parasitic social wasp}

\author{
Kenta Watanabe' , Yudai Nishide' ', Derek A. Roff' ${ }^{2}$ Jin Yoshimura ${ }^{3,4,5}$ \& Kikuo Iwabuchi'
}

${ }^{1}$ Faculty of Agriculture, Tokyo University of Agriculture and Technology, Tokyo 183-8509, Japan, ${ }^{2}$ Department of Biology, University of California, Riverside, CA, 92521 USA, ${ }^{3}$ Department of Systems Engineering, Shizuoka University, Hamamatsu, 432-8561, Japan, ${ }^{4}$ Department of Environmental and Forest Biology, State University of New York College of Environmental Science and Forestry, Syracuse, New York 13210 USA, ${ }^{5}$ Marine Biosystems Research Center, Chiba University, 1 Uchiura, Kamogawa, Chibaken, 299-5502 Japan.

A larval army caste is found in some parasitic wasps with polyembryonic or clonal proliferation, where many clone larvae emerge from a single egg. In contrast to non-parasitic eusocial Hymenoptera, sterile soldier larvae that protect their clonal reproductives are found in both females and males. Recently, the proportion of soldier larvae has been found to vary radically, depending on the internal conditions of the host, such as multiparasitism by other larval parasites. However, the proportion of male soldier larvae is constant, irrespective of the host internal environment. It is unknown if these traits are heritable. Here we show that a high heritability is found in both sexes, while, in the 6th instar hosts, substantially lower heritability is found in females. These results imply that the structure of the larval caste is determined genetically by both female and male embryonic cells, but more likely modified environmentally in females.

ivision of labor is a fundamental feature of social insects ${ }^{1,2}$. It has long been known that the caste structure is affected by environmental factors ${ }^{3,4}$. However, how the caste structure is controlled by genetic and environmental factors is unknown in eusocial insects. In nonparasitic eusocial hymenopterans one of the difficulties is that genetic factors are expressed in at least two decision makers, the queens and workers ${ }^{5,6}$. The separation of genetic from environmental factors is almost impossible in the behavior of workers. Thus the mechanism controlling caste structure is largely unknown in these eusocial insects, although genetic caste determination and specific determinant molecules have recently been demonstrated in other eusocial insects ${ }^{7,8}$.

A polyembryonic parasitoid wasp with sterile solder larval morph is highly suitable for the study of caste structure, because the genetic control is only via the single egg that produces many embryonic clones ${ }^{9}$. In such a system we can determine the extent of genetic control of caste structure by evaluating variation among and within clones with respect to such factors as sex, developmental stage or site of origin. Copidosoma floridanum is a polyembryonic egg-larval parasitoid of Plusiine moths such as Chrysodeixis eriosoma ${ }^{10}$. The female wasp lays one or two eggs into a host egg. As in most hymenopteran species, unfertilized (haploid) eggs produce males and fertilized (diploid) eggs produce females ${ }^{11}$.

The host eggs hatch and undergo six larval instars, during which time, C. floridanum embryos proliferate clonally to form more than 2000 embryos ${ }^{11}$. Most of the embryos develop into reproductive larvae in the sixth (final) instar host larva and finally emerge as adult wasps. In addition to these embryos, a smaller number of embryos develop precociously into morphologically and behaviorally distinct soldier larvae ${ }^{11-13}$. The soldier larvae do not molt and eventually die without pupating ${ }^{11,12}$. The differentiation of two larval morphs occurs as a result of unequal allocation of germ cells to proliferating embryos. Reproductive larvae are produced from the embryos containing germ cells, while the soldier larvae are produced from the embryos without germ cells ${ }^{14}$. In $C$. floridanum, the proportion of sterile soldier larval morphs is known to be affected by the inner environment of the host larva. In particular, female soldiers are found to increase with the existence of heterospecific parasites ${ }^{15-17}$.

We here investigate the genetic background of the caste structure by comparing families and local populations in Japan (Supplementary Figure S1 and Supplementary Table S1). We specifically ask the following three questions: (1) Is there genetic variance in caste structure among local populations? (2) Is caste structure a heritable trait? (3) Does the caste determination system depend on developmental stages and sexes?

\section{Results}

Because they have originated from a single egg, in C. floridanum, all adult wasps emerging from a single dead last instar host (Chrysodeixis eriosoma) larva (mummy) belong to a single clone, and hence all have an identical 
genetic background. Because crosses are between clones the offspring of such crosses are genetically equivalent to full-sibs that share the same parents (Fig. 1a, b). In this paper, we refer to the genetic full-sibs as a "family." The larvae were divided into the following three treatments to count the numbers of soldiers and emerging wasps: (1) dissection at the 3rd instar (early host stage), (2) dissection at the 6th (final) instar (late host stage) and (3) measure the maximum host weight obtained on day 3 of the final instar in order to estimate the number of emerging wasps. Note that the number of emerging wasps (i.e., reproductive larvae) exhibits a strong positive correlation with the host maximum weight ${ }^{12}$. However, it is not known whether the maximum host weight affects the number of soldiers. We examined whether the maximum host weight correlated with the number of soldiers in each family. Unlike the reproductive larvae, we found no significant relationship between the number of soldiers and the host maximum weight in either host stage (Supplementary Fig. S2). Therefore, we ignored the host weight for the current analyses of the number of soldiers.

Before evaluating the genetic control of caste structure, we checked whether there is a genetic variation in the number of soldiers among sampled localities, since these places are 50-100 km apart (Supplementary Figure S1 and Supplementary Table S1). We obtained the samples from these localities and reared their offspring under identical environmental conditions to detect whether there is any genetic variation among localities (Fig. 1c, d, Supplementary Table S2). We detected no significant genetic variation in the number of soldiers among localities. Therefore, we ignored the localities and combined all the localities in the following analyses.

We then compared the number of soldiers within and between families, where a single family share a clone mother. In contrast to the lack of variation among localities, we detected significant variation between family lineages (Fig. 1e, f), indicating that caste structure is a highly heritable trait, with broad sense heritabilities $\left(H^{2}\right)$ ranging from 0.32 to 0.85 (Fig. 2a; Supplementary Table S3). The broad sense heritabilities in female broods are significantly lower $(P<0.05)$ than those in males, possibly reflecting the environmental effects of heterospecific parasites in female progeny (Fig. 2a; Supplementary Table S3, Supplementary Fig. S3). $H^{2}$ in female broods is significantly lower $(P<0.05)$ in the 6th instar host than in the 3rd instar host, possibly reflecting some environmental effects of heterospecific parasites at a later stage in female progeny.

Heterospecific parasites are known to increase female soldiers when they parasitize the host larva at the first and second instars ${ }^{15,16}$. In both male and female soldiers, the coefficients of genetic variation $\left(C V_{G}\right)$ at the 6th host instar are very low compared with those at the 3rd host instar (Fig. 2b). This indicates that the caste structure at the late host stage should be more strongly affected by natural selection ${ }^{18}$. In contrast, the caste structure at the third host instar is a transition that should be highly sensitive to the development and internal condition of a host, such as the growth rates of the host and parasites. At each host stage, the values of $C V_{G}$ are not significantly different between sexes (Fig. 2b), indicating that genetic variation in the number of soldiers is about same between sexes.

The number of soldiers in males was compared with those in females within each family. We found a positive correlation between male and female soldiers at each host stage (early stage: Fig. 3a; and late stage: Fig. $3 \mathrm{~b}$ ). The number of soldiers in males was more variable than that in females at the 3rd host instar. On the other hand, the number of female soldiers was more variable at the 6th host instar. The number of genetically determined female soldiers is about the same as that of males (Fig. 3). Genetic variation in the number of soldiers in both sexes is almost the same despite lower heritability in females at each host stage. This indicates that the production of the soldier caste in females is phenotypically variable and may respond to the host larval environmental factors (Fig. 2a). These results confirm that the sexual asymmetry in the responsiveness to the host larval
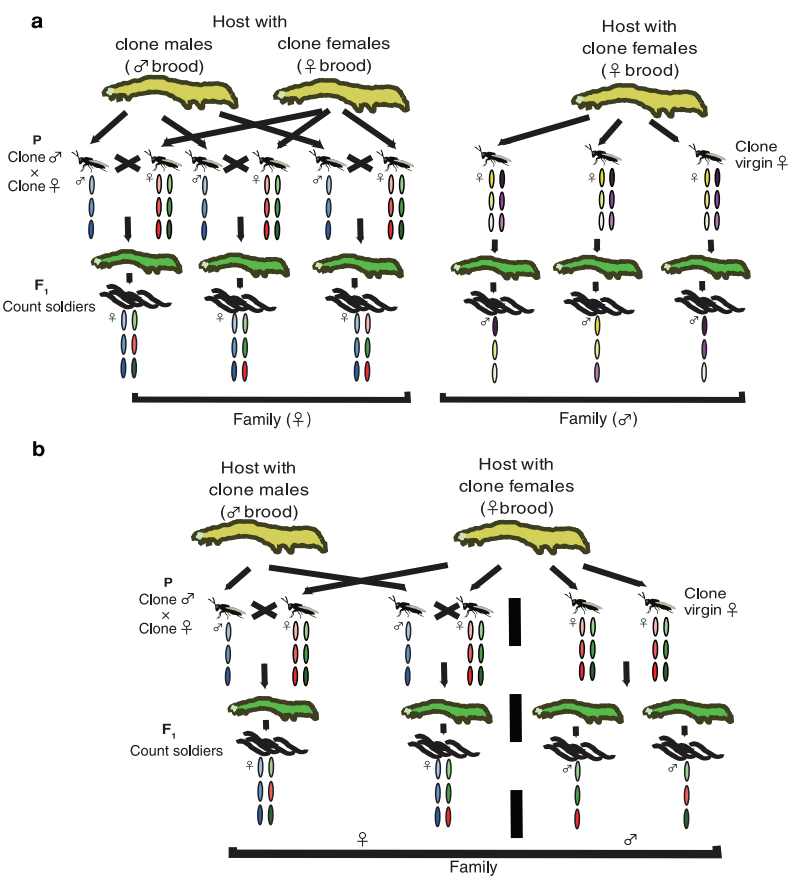
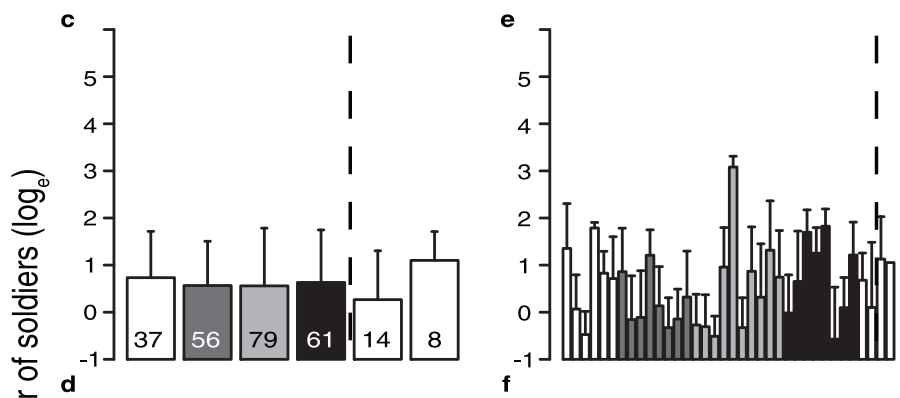

f
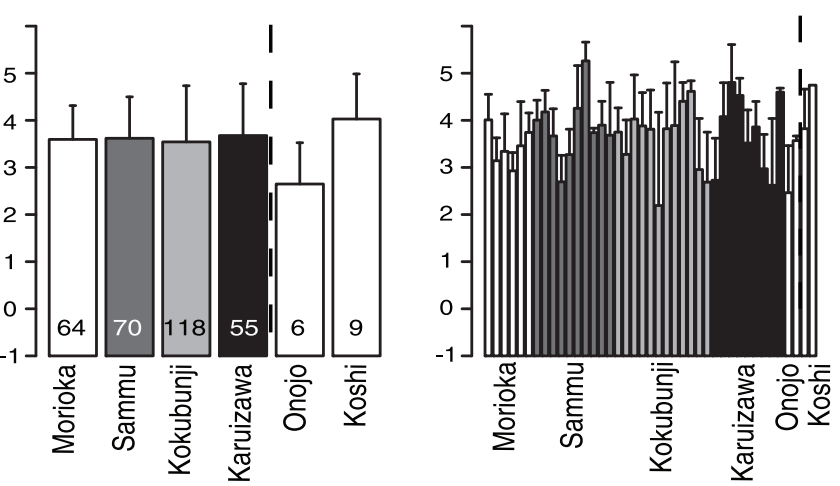

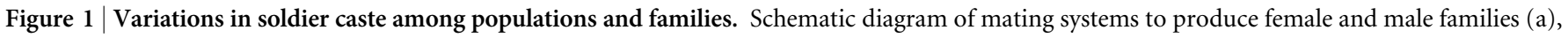

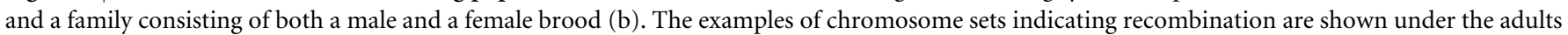
and solder larvae. Mean number of soldiers among populations at the 3rd host instar (c) and at the 6th host instar (d), and among families within a

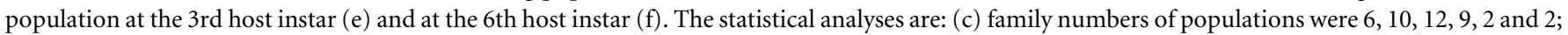

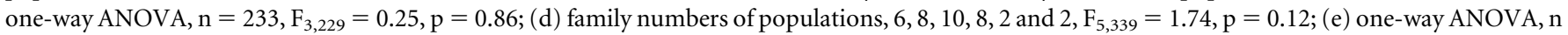

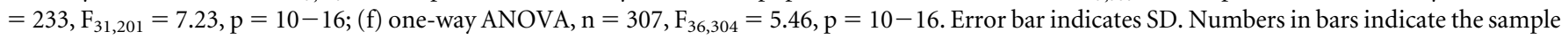
size ( $c$ and d). The populations from Onojo and Koshi cities are excluded from statistical analyses of families because of small sample size. 

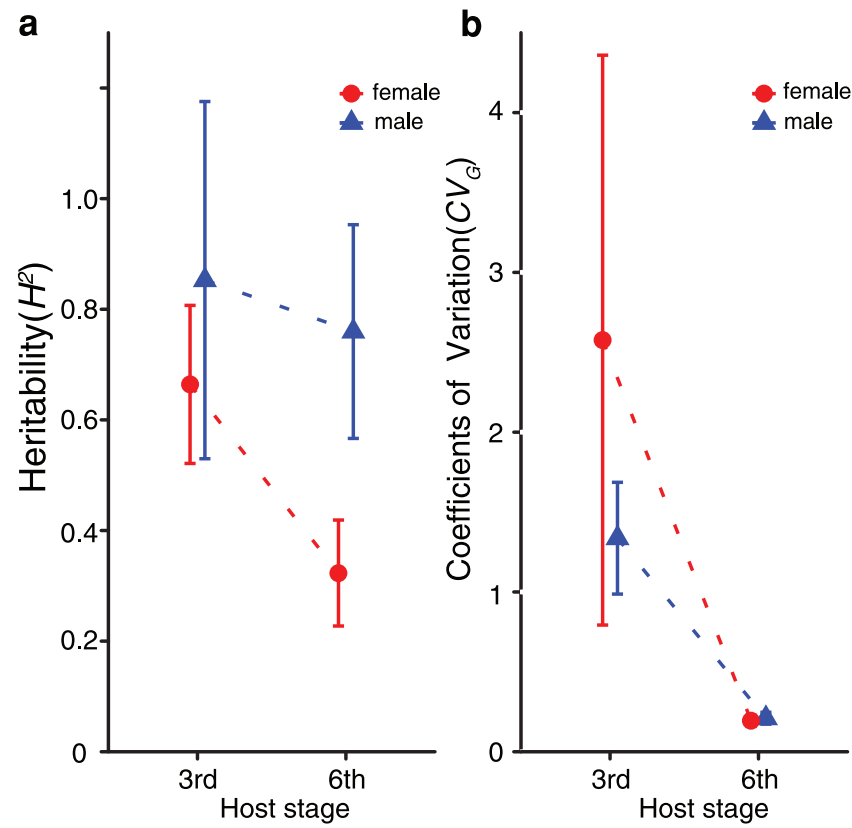

Figure $2 \mid$ Heritability $\left(H^{2}\right)$ and $C V G$ in the number of soldiers at the 3 rd and 6 th host instars. The heritability (a) and coefficients of genetic variations (b) in males (blue triangle) and females (red circle) estimated from a full-sib analysis are shown with error bars indicating standard errors estimated with the jackknife procedure ${ }^{33}$. All estimated heritabilities are significantly different from zero. The heritability of females at the 6th host instar is significantly different from both that of females at the $3 \mathrm{rd}$ host instar and that of males at the 6th instar. See Supplementary Table S3 in Supplementary Information for detail data.

environment originated from genetic differences in male and female soldiers.

\section{Discussion}

Eusociality has evolved in various insect taxa independently and repeatedly ${ }^{19}$. The structure and function of castes vary among these $\operatorname{taxa}^{20}$ : the frequent independent evolution of eusociality indicates that there should be some common ecological/evolutionary conditions that favour it. However, it is difficult to evaluate the genetic control of caste structure, because of difficulties in resolving genetic variation in diploid non-clonal species and the complicated caste structures in these systems $\mathrm{s}^{21-23}$ (see also Supplementary Table S4). Because of clonal proliferation, polyembryonic parasitic wasps are highly suitable for the study of the genetic control of caste structure. The genus Copidosoma is the only parasitoid genus in which many species are known to produce soldier morphs ${ }^{24-26}$. Some species produce only female soldiers, whereas others produce both male and female soldiers. The number of soldiers varies greatly among species. Copidosoma floridanum, the species that is the subject of this study is one of the most advanced species with both male and female soldiers produced in huge numbers. In particular, the Japanese strain produces large numbers of both male and female soldiers ${ }^{16}$.

The current results indicate how caste structure is controlled in this polyembryonic parasitoid. We found genetic control of solder larvae in both sexes, and substantial plasticity in females at the late host stages. The male soldiers are mostly determined genetically, whereas the number of female soldiers is more affected by environmental factors such as heterospecific parasites. Whether the plasticity in females is adaptive remains to be determined. Female fitness, in general, is a function of the number of offspring produced, while male fitness is a function of the number of females fertilized ${ }^{27}$. Therefore, selection will favor, all other things being equal, females a
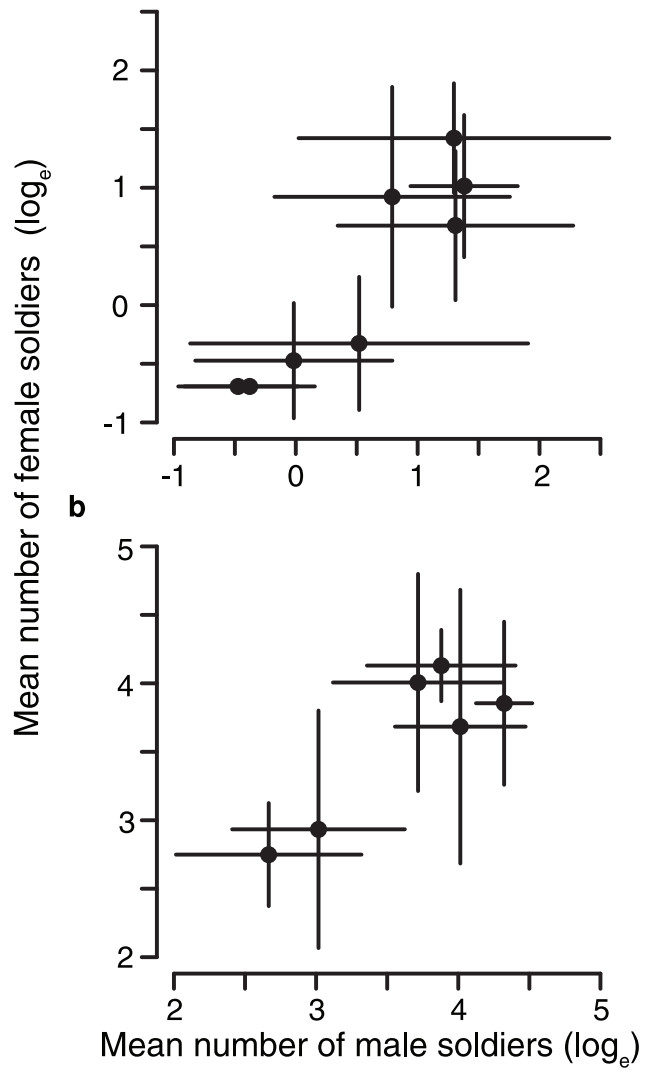

Figure 3 Positive correlations in the male and female soldier numbers of a family. (a) 3rd host instar (Pearson's product-moment correlation test, $r=0.92$, No. of families $=6, p=0.001$ ). (b) 6th host instar (Pearson's product-moment correlation test, $r=0.87$, No. of families $=8, p=0.02$ ). The population sizes of male soldiers are significantly correlated with those of females in the same family at the 3rd and 6th host instars. Each point indicates the mean numbers of soldiers (log-transformed) in each family and bars indicate SD.

that show the greatest care in selection of their oviposition sites or care of their offspring. Variation in environmental conditions will, therefore, select for females that respond appropriately in such decisions with variation in the environment. Because only female soldiers protect their clone mates ${ }^{28}$, in this species sexual conflict occurs when the female lays two eggs (female and male eggs) in the same host egg. The findings in the present study on the genetic basis of caste structure, may provide novel insights in our understanding of the evolution of soldier larvae in polyembryonic parasitoids.

In this species, the genetic mechanism for phenotypic plasticity in larvae is unknown. Recently, it has been found that caste differentiation in honeybees is controlled by genomic imprinting via DNA methylation $^{29}$. Such epigenetic control could be the mechanism of quantitative control of soldiers in this species. For example, genes expressed in germ cells necessary for reproductive larva could be epigenetically modified by environmental conditions, resulting in soldier larvae. However, the phenotypic plasticity in the soldiers may be achieved simply by the stimulated cell division of the soldier-larval embryos that is induced transiently by a particular environmental factor.

We also found that genetic variation of soldier numbers is smaller at late host stages than that at early host stages. This suggests that selection on the number of soldiers at late host stages has been stronger than at the early stage. In this regard it can be noted that the soldiers at late host stages play an important role in the defense against other parasitoids ${ }^{16,30}$. Because of non-additive effects not 
being entirely excluded, broad sense heritability $\left(H^{2}\right)$ as used here may overestimate the narrow sense heritability ${ }^{31,32}$. In the current system, the degree of overestimation should be much less in males because dominance occurs in diploids, but not in haploids (males).

\section{Methods}

We produced the families as follows (Fig. 1a and 1b). Clone females (i.e. females that were the product of a single egg, emerging from the same host) were individually mated once with clone males (i.e. males that were the product of a single egg, emerging from the same host). To produce the male family virgin females were used. These females were allowed to parasitize a host only once. The number of soldiers was evaluated as follows (Fig. 1c-1f). We measured the number of soldiers from the parasitized hosts at the 3rd instar and at the 6th instar, and the maximum weight of the host. To minimize the genetic background, females originating from the same host (hence the same clone) were used. The populations from Onojo and Koshi cities were excluded from the statistical analyses of families because of their small sample sizes (see Supplementary Fig. S1). For more detailed descriptions of materials and methods, see the supplementary method details in the Supplementary Information.

1. Wilson, E. O. The Insect Societies (Harvard Univ. Press, Cambridge, MA, 1971)

2. Wilson, E. O. The Sociogenesis of Insect Colonies. Science 228, 1489-1495 (1985).

3. Wheeler, D. E. Developmental and Physiological Determinants of Caste in Social Hymenoptera: Evolutionary Implications. Am. Nat. 128, 13 (1986).

4. Schwander, T. et al. Nature versus nurture in social insect caste differentiation. Trends Ecol. Evol. 25, 275-282 (2010).

5. Trivers, R. L. \& Hare, H. Haploidploidy and the evolution of the social insect. Science 191, 249-263 (1976).

6. Passera, L., Aron, S., Vargo, E. L. \& Keller, L. Queen Control of Sex Ratio in Fire Ants. Science 293, 1308-1310 (2001).

7. Schwander, T., Lo, N., Beekman, M., Oldroyd, P. \& Keller, L. Nature versus nurture in social insect caste differentiation. Trends Ecol. Evol. 25, 275-282 (2010).

8. Kamakura, M. Royalactin induces queen differentiation in honeybees. Nature 473, 478-483 (2011).

9. Cruz, Y. P. A sterile defender morph in a polyembryonic hymenopterous parasite. Nature 294, 446-447 (1981).

10. Noyes, J. S. Copidosoma truncatellum (Dalman) and C. floridanum (Ashmead) (Hymenoptera, Encyrtidae), two frequently misidentified polyembryonic parasitoids of caterpillars (Lepidoptera). System. Entomol. 13, 197-204 (1988).

11. Ode, P. J. \& Strand, M. R. Progeny and sex allocation decisions of the polyembryonic wasp Copidosoma floridanum. J. Anim. Ecol. 64, 213-224 (1995).

12. Utsunomiya, A. \& Iwabuchi, K. Interspecific competition between the polyembryonic wasp Copidosoma floridanum and the gregarious endoparasitoid Glyptapanteles pallipes. Entomol. Exp. Appl. 104, 353-362 (2002).

13. Grbic, M., Ode, P. J. \& Strand, M. R. Sibling rivalry and brood sex ratios in polyembryonic wasps. Nature 360, 254-256 (1992).

14. Zhurov, V., Terzin, T. \& Grbic, M. Early blastomere determines embryo proliferation and caste fate in a polyembryonic wasp. Nature 432, 764-768 (2004).

15. Harvey, J. A., Corley, L. S. \& Strand, M. R. Competition induces adaptive shifts in caste ratios of a polyembryonic wasp. Nature 406, 183-186 (2000).

16. Yamamoto, D., Henderson, R., Corley, L. S. \& Iwabuchi, K. Intrinsic, inter-specific competition between egg, egg-larval, and larval parasitoids of plusiine loopers. Ecol. Entmol. 32, 221-228 (2007).

17. Gordon, S. D. \& Strand, M. R. The polyembryonic wasp Copidosoma floridanum produces two castes by differentially parceling the germ line to daughter embryos during embryo proliferation. Dev. Genes Evol. 219, 445-454 (2009).

18. Houle, D. Comparing evolvability and variability of quantitative traits. Gentics 130, 195-204 (1992)

19. Choe, J. \& Crespi, B. J. The evolution of social behavior in insects and arachnids. (Cambridge, UK. Cambridge University Press, 1997).
20. Oster, G. F. \& Wilson, E. O. Caste and Ecology in the Social Insects (Princeton Univ. Press, Princeton, New Jersey, 1978).

21. Hayashi, Y., Lo, N., Miyata, H. \& Kitade O. Sex-linked genetic influence on caste determination in a termite. Science 318, 985-987 (2007).

22. Schwander, T. \& Keller, L. Genetic compatibility affects queen and worker caste determination. Science 322, 552 (2008).

23. Libbrecht, R., Schwander, T. \& Keller, L. Genetic components to caste allocation in a multiple-queen ant species. Evolution 65, 2907-2915 (2011).

24. Guerrieri, E. \& Noyes, J. Revision of the European species of Copidosoma Ratzeburg (Hymenoptera: Encyrtidae), parasitoids of caterpillars (Lepidoptera). Systematic Entomology 30, 97-174 (2005).

25. Keasar, T. et al. Costs and consequences of superparasitism in the polyembryonic parasitoid Copidosoma koehleri (Hymenoptera: Encyrtidae) Ecol. Entomol. 31, 277-283 (2006)

26. Smith, M. S., Milton, I. \& Strand, M. R. Phenotypically plastic traits regulate caste formation and soldier function in polyembryonic wasps. J. Evol. Biol. 23, 26772684 (2010).

27. Trivers, R. L. in Sexual Selection and the Descent of Man (ed Campbell, B.) 136-179 (Heinemann, London, 1972).

28. Giron, D., Harvey, J. A., Johnson, J. A. \& Strand, M. R. Male soldier caste larvae are non-aggressive in the polyembryonic wasp Copidosoma floridanum. Biol. Lett. 3, 431-434 (2007)

29. Kucharski, R. et al. Nutritional control of reproductive status in honeybees via DNA methylation. Science 319, 1827-1830 (2008).

30. Giron, D., Ross, K. G. \& Strand, M. R. Presence of soldier larvae determines the outcome of competition in a polyembryonic wasp. J. Evol. Biol. 20, 165-172 (2007).

31. Visscher, P. M., Hill, W. G. \& Wray, N. R. Heritability in the genomics era concepts and misconceptions. Nat. Rev. Genet. 9, 255-266 (2008).

32. Kruuk, L. E. B. \& Hadfield, J. D. How to separate genetic and environmental causes of similarity between relatives. J. Evol. Biol. 20, 1890-1903 (2007).

33. Roff, D. A. Introduction to Computer-Intensive Methods of Data Analysis in Biology. (Cambridge University Press, Cambridge, 2006)

\section{Acknowledgments}

We thank K. Takashino, M. Nomura and H. Takeuchi for the help in collecting samples. This work is supported in parts by the Grants-in-Aid for Scientific Research from Japan Society for the Promotion of Science to KI (no. 20380032) and J.Y. (nos.22255004 and 22370010). The founder has no role in study design, data collection and analysis, decision to publish, or preparation of the manuscript. No additional external funding received for this study. The authors were solely responsible for the design, conduct, and interpretation of all studies.

\section{Author contributions}

K. W. and K. I. designed and performed the experiments and analyzed the data; Y. N., D. R. and J. Y. performed the statistical analyses of the data. Y. N., D. R., J. Y. and K. I. provided conceptual insight; K.W., D. R., J. Y. and K. I. prepared the manuscript.

\section{Additional information}

Supplementary information accompanies this paper at http://www.nature.com/ scientificreports

Competing financial interest: The authors declare no competing financial interests.

License: This work is licensed under a Creative Commons

Attribution-NonCommercial-ShareAlike 3.0 Unported License. To view a copy of this license, visit http://creativecommons.org/licenses/by-nc-sa/3.0/

How to cite this article: Watanabe, K., Nishide, Y., Roff, D.A., Yoshimura, J. \& Iwabuchi, K. Environmental and genetic controls of soldier caste in a parasitic social wasp. Sci. Rep. 2, 729; DOI:10.1038/srep00729 (2012) 